\title{
COD Removal Model and Its Application in Shallow Soil Infiltration Treatment System
}

\author{
ZHENYA ZHANG ${ }^{1}$, ZHIYIN ZHANG ${ }^{2}$, ZHONGFANG LEI ${ }^{2 *}$, and NORIO SUGIURA ${ }^{1}$ \\ ${ }^{1}$ Graduate School of Life Environmental Sciences, Tsukuba University \\ /1-1-1 Tennodai, Tsukuba, Ibaraki 305-8572, Japan \\ ${ }^{2}$ Department of Environmental Science and Engineering, Fudan University \\ /220 Handan Road, Shanghai 200433, China
}

\begin{abstract}
Soil infiltration treatment (SIT) system commonly exhibited effective chemical oxygen demand (COD) removal, but few researches were focused on COD removal models. In shallow soil infiltration treatment (SSIT) systems, COD removal could be simulated by an integrated COD removal model with the effects of influent COD concentration $\left(S_{0}\right)$, water temperature $(T)$ and nondegradable COD portion $\left(S_{n}\right)$ on COD removal being incorporated into Eckenfelder Model. The results showed that the deviations could be within $5 \mathrm{mg} \boldsymbol{t}^{-1}$ for $95 \%$ of the data obtained from simulation and experiment when the integrated COD removal model being applied. This model can be used in the evaluation, analysis, prediction and management of COD removal in SSIT systems within the model application limits.
\end{abstract}

Key words: shallow soil infiltration treatment (SSIT) system, chemical oxygen demand (COD) removal, model

\section{NOMENCLATURE}

BOD: biochemical oxygen demand, $\mathrm{M} \mathrm{L}^{-3}$

$\mathrm{BOD}_{5}$ : 5-day biochemical oxygen demand, $\mathrm{M} \mathrm{L}^{-3}$

$C$ : substituting symbol in parameter estimation

$C_{0}$ : influent BOD concentration, $\mathrm{M} \mathrm{L}^{-3}$

$C_{e}$ : effluent BOD concentration, $\mathrm{M} \mathrm{L}^{-3}$

COD: chemical oxygen demand, $\mathrm{M} \mathrm{L}^{-3}$

DOC: dissolved organic carbon, $\mathrm{M} \mathrm{L}^{-3}$

$f$ : soil characteristic coefficient

$H$ : effective depth of soil infiltration trench, $\mathrm{L}$

$K_{1}$ : BOD removal rate constant in Model $1, \mathrm{~T}^{-1}$

$K_{2}$ : BOD removal rate constant at $20^{\circ} \mathrm{C}$ in Model $2, \mathrm{~T}^{-1}$

$K_{3}$ : COD removal rate constant at $20^{\circ} \mathrm{C}$ in Model $3, \mathrm{~T}^{-1}$

$K_{4}$ : COD removal rate constant in Model $4, \mathrm{~L}^{3}$ $\mathrm{M}^{-1} \mathrm{~T}^{-1}$

$K_{5}$ : COD removal rate constant at $20^{\circ} \mathrm{C}$ in Model $5, \mathrm{~L}^{3} \mathrm{M}^{-1} \mathrm{~T}^{-1}$

$K_{6}$ : COD removal rate constant at $20^{\circ} \mathrm{C}$ in Model $6, \mathrm{~L}^{3} \mathrm{M}^{-1} \mathrm{~T}^{-1}$

$m$ : influent COD concentration coefficient $n$ : sampling time

$\mathrm{NH}_{4}{ }^{+}-\mathrm{N}$ : ammonia nitrogen, $\mathrm{M} \mathrm{L}^{-3}$

$q$ : hydraulic loading rate, $\mathrm{L}^{3} \mathrm{~L}^{-2} \mathrm{~T}^{-1}$

$R D_{\text {avg: }}$ average relative deviation

$S_{0}$ : influent COD concentration, $\mathrm{M} \mathrm{L}^{-3}$

$S_{e}$ : effluent COD concentration, $\mathrm{M} \mathrm{L}^{-3}$

$S_{e}$ : simulated value of effluent COD concentration, $\mathrm{M} \mathrm{L}^{-3}$

$S_{n}$ : nondegradable COD portion, $\mathrm{M} \mathrm{L}^{-3}$

$S D$ : standard deviation

SS: suspended solid, $\mathrm{M} \mathrm{L}^{-3}$

SIT: soil infiltration treatment

SSIT: shallow soil infiltration treatment

Ti: $\operatorname{trench}(\mathrm{i}=1,2,3,4)$

$T$ : water temperature in SSIT system, ${ }^{\circ} \mathrm{C}$

$\mathrm{T}-\mathrm{N}$ : total nitrogen, $\mathrm{M} \mathrm{L}^{-3}$

$\mathrm{T}-\mathrm{P}$ : total phosphorus, $\mathrm{M} \mathrm{L}^{-3}$

$\theta$ : temperature coefficient of COD removal

\section{INTRODUCTION}

Soil infiltration treatment (SIT) system has been proved to be a good alternative for

*Corresponding author 
wastewater treatment in situ with effective removal of organic compounds, nitrogen, phosphorus and etc. through infiltration, percolation, sorption, chemical reaction, biotransformation, die-off, predation and plant uptake $\mathrm{e}^{1-3)}$. Up to now, SIT technology has been widely used for water source protection, polluted water treatment and wastewater reuse in the United States, France, Israel and other countries ${ }^{4-7}$. It can also be applicable in China ${ }^{8)}$. As to SIT modeling, most researches were focused on soil infiltrability ${ }^{9,10)}$, pollutant transport ${ }^{11,12)}$ and optimal operations ${ }^{13,14)}$. However, few researches were concentrated on pollutant removal models.

The SIT systems usually used in field studies were typically designed with effective depths of SIT trenches larger than $0.6 \mathrm{~m}$ (always range from $0.6 \mathrm{~m}$ to $1.2 \mathrm{~m}$ ). However, based on the researches of Van Cuyk, et al. ${ }^{2}$ and Oudot, et al. ${ }^{15)}$, biological degradation was active within the infiltration zone from 0 $\mathrm{cm}$ to $15 \mathrm{~cm}$ depth and in the upper $30 \mathrm{~cm}$ layer of soils. Some laboratory studies reported that effective pollutant removals could also be obtained within soil depth varied from $40 \mathrm{~cm}$ to $50 \mathrm{~cm}^{16,17)}$. And the design and application of shallow soil infiltration treatment (SSIT) is necessary for the consideration of construction costs and groundwater protection.

The objective of this paper was to concentrate on establishing COD removal model in SSIT systems by modifying Eckenfelder Model, using the experimental data under various operation conditions through a field program. In this study, COD removal models were proposed for different SSIT systems and modified with the effects of influent COD concentration, water temperature and nondegradable COD portion being considered.

\section{MATERIALS AND METHODS}

Field facilities and artificial soil constituents The SSIT system in the field was composed of pre-aeration tank, sedimentation tank, four infiltration trenches, influent and effluent facilities (Fig. 1). Four trenches (labeled as $\mathrm{T} 1, \mathrm{~T} 2, \mathrm{~T} 3$ and T4) were designed in parallel, with total and effective depth about $0.5 \mathrm{~m}$ and $0.3 \mathrm{~m}$, respectively ${ }^{18)}$. Different artificial soil constituents used in the four different SSIT systems are listed in Table 1.

Operation conditions The field SSIT systems were started up in Nov. 2005 and detailed experiments were conducted from Feb. to Aug. in 2006 during which the systems became mature gradually. Five runs were arranged with the consideration of different hydraulic loading rates, influent pollutant concentrations, wetting/drying period ratios and temperatures (Table 2).

The influent in this study was a combined wastewater, consisted of domestic wastewater (from toilets, restaurants, etc.) and wastewater from a nearby gas station. The ranges of major water quality indices for the influent were COD 53-180 $\mathrm{mg} l^{-1}$, $\mathrm{pH}$ 7.06-7.18, suspended solid (SS) 34-65 $\mathrm{mg} l^{-1}$, total nitrogen $(\mathrm{T}-\mathrm{N}) \quad 8.5^{-21.4} \mathrm{mg} l^{-1}$, ammonia nitrogen $\left(\mathrm{NH}_{4}{ }^{+} \mathrm{N}\right)$ 4.9-14.0 $\mathrm{mg} l^{-1}$ and total phosphorus (T-P) $0-7.7 \mathrm{mg} \quad l^{-1}$, with an

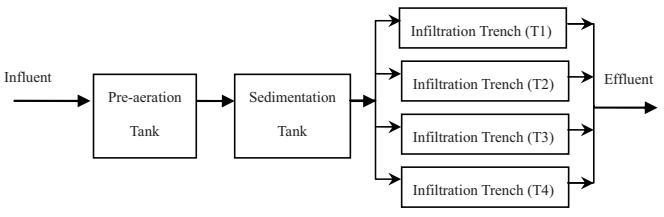

Fig. 1 Schematic flowchart of the SSIT System

Table 1 Constituents for the four infiltration trenches (SSIT) in the field

\begin{tabular}{lcccc}
\hline \multicolumn{1}{c}{ Items } & T1 & T2 & T3 & T4 \\
\hline Artificial Soil Composition & & & & \\
Local soil (\%) & 70 & 60 & 60 & 60 \\
Coal slag (\%) & 20 & 20 & 20 & 20 \\
Dewatered sludge (\%) & 10 & 10 & 10 & 10 \\
Packing medium (\%) & - & 10 (sawdust) & 10 (anthracite) & 10 (zeolite) \\
\hline
\end{tabular}

The percentage is indicated as volume ratio and the dimension of packing medium used was $1 \mathrm{~cm}-3 \mathrm{~cm}$ in diameter. 
Table 2 Operation conditions selected in the field study (from Feb. to Aug. in 2006)

\begin{tabular}{|c|c|c|c|c|c|}
\hline \multirow{2}{*}{ Parameters } & \multicolumn{5}{|c|}{ Runs } \\
\hline & $\mathrm{I}$ & II & III & IV & $\mathrm{V}$ \\
\hline Date (month.day) & $2.5^{-2.20}$ & $2.27-3.16$ & $3.18-6.27$ & $7.5^{-7.19}$ & $7.27-8.10$ \\
\hline Air temperature $\left({ }^{\circ} \mathrm{C}\right)$ & $0.0-21.8$ & $6.0-19.3$ & $14.0-37.0$ & $30.0-37.0$ & $33.0^{-} 37.0$ \\
\hline Water temperature $T\left({ }^{\circ} \mathrm{C}\right)$ & $6.9-12.2$ & $11.7-20.6$ & $12.6^{-} 32.5$ & $22.2-31.4$ & $29.7-30.5$ \\
\hline Hydraulic loading rate $q\left(\mathrm{~m}^{3} \mathrm{~m}^{-2} \mathrm{~d}^{-1}\right)$ & 0.038 & 0.019 & 0.038 & 0.100 & 0.038 \\
\hline COD after pretreatment(mg $\left.l^{-1}\right)$ & $60-95$ & $45^{-70}$ & $49-93$ & $42-72$ & $67-98$ \\
\hline $\mathrm{NH}^{+}{ }_{4}-\mathrm{N}$ after pretreatment $\left(\mathrm{mg} l^{-1}\right)$ & $6.15^{-11.95}$ & $6.90-8.95$ & $6.15^{-12.10}$ & $7.00-12.40$ & $7.80-10.40$ \\
\hline $\mathrm{T}-\mathrm{P}$ after pretreatment $\left(\mathrm{mg} l^{-1}\right)$ & $0.00-5.48$ & $0.00-0.31$ & $0.00-0.40$ & $0.26-0.30$ & $0.15^{-0.29}$ \\
\hline Effluent COD from SSIT (mg $\left.l^{-1}\right)$ & $30-41$ & $27-41$ & $24-40$ & $22-27$ & $28^{-35}$ \\
\hline Wetting/drying period ratio (hr:hr) & $1: 2$ & $1: 5$ & $1: 2$ & $1: 2$ & $1: 2$ \\
\hline Sampling times & 7 & 6 & 20 & 7 & 4 \\
\hline
\end{tabular}

average ratio 0.6 for 5 -day biochemical oxygen demand $\left(\mathrm{BOD}_{5}\right) / \mathrm{COD}$. The main characteristics of wastewater after pretreatment were shown in Table 2, which was regarded as the influent of SSIT system in the modeling.

Sampling and analytical method The influent and effluent samples were collected once every two or three days after the system became stable in each run. Air temperature and water temperature were recorded at the same time. All the samples were stored at $4^{\circ} \mathrm{C}$ and analyzed within $24 \mathrm{~h}$.

$\mathrm{COD}\left(\mathrm{K}_{2} \mathrm{Cr}_{2} \mathrm{O}_{7}\right.$ method) was measured by following the method of No.14540 of WTW Photolab S12 (Germany) and used to evaluate the total amount of organics in wastewater.

\section{MODELS AND MODIFICATIONS}

Eckenfelder Model The removal processes in SIT were generally in accord with the first-order kinetics formulas of biofilm treatment models ${ }^{19,20)}$. The pollutant (COD, BOD or $\mathrm{NH}_{4}{ }^{+}-\mathrm{N}$, etc.) concentration in wastewater decreased through soil layer from top to bottom. Eckenfelder Model was one of the first-order kinetics models proposed by Eckenfelder in $1961^{20)}$, which pointed out that the pollutant removal not only closely correlated with infiltration layer, e.g., the pollutant concentration decreased with the depth of infiltration soil layer by a first-order reaction, but also had some relationship with the characteristics of infiltration medium and hydraulic loading rate being applied. Using artificial soil as infiltration medium in this study, Eckenfelder Model is applied for SSIT systems as Model 1.

$$
C_{e}=C_{0} e^{-K_{1} H q^{-f}}
$$

In which, $C_{0}$ and $C_{e}$ are the influent and effluent BOD concentrations (M $\mathrm{L}^{-3}$ ), respectively, $H$ is the effective depth of soil infiltration trench (L) (here $H=0.3 \mathrm{~m}$ ), and $q$ is the hydraulic loading rate $\left(\mathrm{L}^{3} \mathrm{~L}^{-2} \mathrm{~T}^{-1}\right)$. $K_{1}$ (BOD removal rate constant, $\mathrm{T}^{-1}$ ) and $f$ (soil characteristic coefficient) can be regarded as constants in a determined SSIT system.

As it is known, water temperature has some effect on BOD removal rate constant $K_{1}{ }^{20)}$, thus Eckenfelder Model can be firstly rewritten as Model 2 according to Arrhenius experiential calculation formula,

$$
C_{e}=C_{0} e^{-K_{2} 1.035^{T-20} H q^{-f}}
$$

where, $K_{2}=$ BOD removal rate constant at $20^{\circ} \mathrm{C}\left(\mathrm{T}^{-1}\right), \quad T$ =water temperature in SSIT system $\left({ }^{\circ} \mathrm{C}\right)$ and $1.035=$ temperature coefficient of BOD removal.

Modification of Eckenfelder Model In SSIT systems, abiological effect was evident and contributed to $28.1 \%-42.3 \%$ of the total COD removal, which increased with the increase of water temperature ${ }^{18)}$. COD, more convenient and easier to determine than BOD, is always used to measure the total organics in wastewater. Recently, COD, instead of BOD, has been frequently and successfully used in the Eckenfelder models of biological aerated filters for the treatment 
of domestic wastewater ${ }^{21-24)}$, and it has been noticed that the exponent $(f)$ of hydraulic loading rate $(q)$ was different when various parameters being used in Eckenfelder trickling filter models to estimate the organic matter content in the same wastewater (e.g., $\mathrm{BOD}_{5}, \quad \mathrm{COD}$ or $\left.\mathrm{TOC}\right)^{25}$. Therefore the feasibility is worthy of investigation when Eckenfelder Model is applied to simulate the COD removal in SSIT systems, and the following aspects should be considered before application with respect to the shallow depth of artificial soil.

At first, the 1.035 in Model 2 was used for BOD removal and the effect of temperature on COD removal might be different due to the fact that a substantial portion $\left(28.1 \%^{-}\right.$ $42.3 \%$ ) of COD removal is contributed by abiological proceses ${ }^{18)}$. Thus considering the impact of temperature on COD removal and the difference existed among the four SSIT systems, the Model 2 is rewritten as Model 3 ,

$$
S_{e}=S_{0} e^{-K_{3} \theta^{T-20} H q^{-f}}
$$

where $S_{0}$ and $S_{e}$ are the influent and effluent COD concentrations $\left(\mathrm{M} \mathrm{L}^{-3}\right)$, respectively, $K_{3}$ is the COD removal rate constant at $20^{\circ} \mathrm{C}$ $\left(\mathrm{T}^{-1}\right)$, and $\theta$ is the temperature coefficient of COD removal.

Secondly, the influence of influent COD must be included. In order to identify the stability of COD removal performance of the four SSIT systems, the effect of influent COD concentration on effluent quality was paid more attention because of the shallow depth of soil matrix in spite of the findings of Zhang J., et al. ${ }^{26)}$ and Nema P., et al. ${ }^{27)}$ in SIT systems, in which the relationship between influent COD and effluent COD seemed to be conflicting. Furthermore, the influent COD concentration has been successfully introduced into the COD and $\mathrm{NH}_{3}-\mathrm{N}$ removal models of aerobic biofilm filter bed system ${ }^{28}$. So far, the Model 3 could be rewritten as Model 4, which is more complicated than the original Eckenfelder Model,

$$
S_{e}=S_{0} e^{-K_{4} H q^{-f} S_{0}{ }^{m}}
$$

where $K_{4}=\mathrm{COD}$ removal rate constant $\left(\mathrm{L}^{3}\right.$ $\mathrm{M}^{-1} \mathrm{~T}^{-1}$ ) and $m=$ influent COD concentration coefficient.

When the effects of temperature and influent COD being considered together, COD removal model could be further rewritten as Model 5,

$$
S_{e}=S_{0} e^{-K_{5} \theta^{T-20} H q^{-f} S_{0}{ }^{m}}
$$

where $K_{5}=$ the COD removal rate constant at $20^{\circ} \mathrm{C}\left(\mathrm{L}^{3} \mathrm{M}^{-1} \mathrm{~T}^{-1}\right)$.

At last, dissolved organic carbon (DOC) in influent always included some nondegradable components ${ }^{29}$, and COD removal potential for SSIT system might have its limit even though physico-chemical and biological COD removal mechanisms usually coexisted in artificial soil. Thus nondegradable COD portion $S_{n}$, an indicator of the COD removal limit (or potential) for SSIT system, was introduced into Model 5 and a relatively integrated COD removal model could be concluded as Model 6.

$$
S_{e}=\left(S_{0}-S_{n}\right) e^{-K_{6} \theta^{T-20} H q^{-f}\left(S_{0}-S_{n}\right)^{m}}+S_{n}
$$

In which, $K_{6}$ is the COD removal rate constant at $20^{\circ} \mathrm{C}\left(\mathrm{L}^{3} \mathrm{M}^{-1} \mathrm{~T}^{-1}\right)$, and $S_{n}$ is the nondegradable $\mathrm{COD}$ portion $\left(\mathrm{M} \mathrm{L} \mathrm{L}^{-3}\right)$ of wastewater through SSIT system. Because the same influent was injected simultaneously into the four SSIT systems in this study, the $S_{n}$ value obtained could imply the performance of COD removal for various SSIT systems.

Evaluation of the models The fitness of each COD removal model (Models 1-6) was evaluated according to standard deviation $(S D)$ and average relative deviation $\left(R D_{\text {avg }}\right)$ between the values of simulation and experiment. $S D$ and $R D_{\text {avg }}$ could be calculated from Equations $7^{30)}$ and 8, respectively,

$$
\begin{aligned}
& S D=\sqrt{\frac{\sum\left(S_{e}-S_{e}^{\prime}\right)^{2}}{n-2}} \\
& R D_{\text {avg }}(\%)=\sum\left|\frac{S_{e}-S_{e}^{\prime}}{S_{e}}\right| \times 100 / n
\end{aligned}
$$

where $S_{e}^{\prime}=$ simulated value of effluent COD concentration (M L ${ }^{-3}$ ) and $n$ =sampling times. 


\section{RESULTS AND DISCUSSION}

Estimation of parameters in models Model 1 can be rewritten as Equation (9) by taking the natural logarithm to each side of Equation (1), and Equation (10) can be obtained by transposition and a secondary logarithm transformation.

$$
\begin{aligned}
& \ln \left(C_{e}\right)=\ln \left(C_{0}\right)-K_{1} H q^{-f} \\
& \ln \frac{\ln \left(C_{e}\right)-\ln \left(C_{0}\right)}{-H}=\ln \left(K_{1}\right)-f \ln (q)
\end{aligned}
$$

If $\frac{\ln \left(C_{e}\right)-\ln \left(C_{0}\right)}{-H}$ is lumped as $C$, Equation (10) may be simplified as Equation (11):

$$
\ln (C)=-f \ln (q)+\ln \left(K_{1}\right)
$$

Plotting the $\ln (C)$ versus $\ln (q)$ gives the estimates of slope and interception from the linear curve, which are numerically equal to $f$ and $\ln \left(K_{1}\right)$. Taking $\mathrm{T} 1$ trench as an example (Fig. 2), it can be seen that $-f=0.3275$ and $\ln \left(K_{1}\right)=1.8906$. So the values of the soil characteristic coefficient $f(=-0.3275)$ and BOD removal rate constant $K_{1}(=6.6233)$ in Model 1were obtained for T1 trench.

The estimation of parameters in Model 2 can follow the same procedures as in Model 1. For the Models $3 \sim 6$, only the experimental data were used when $q=0.038 \mathrm{~m}^{3} \mathrm{~m}^{-2} \mathrm{~d}^{-1}$ and $q^{-f}$ was regarded as constant in a determined system.

In Model $3, K_{3}$ and $\theta$ can be estimated by

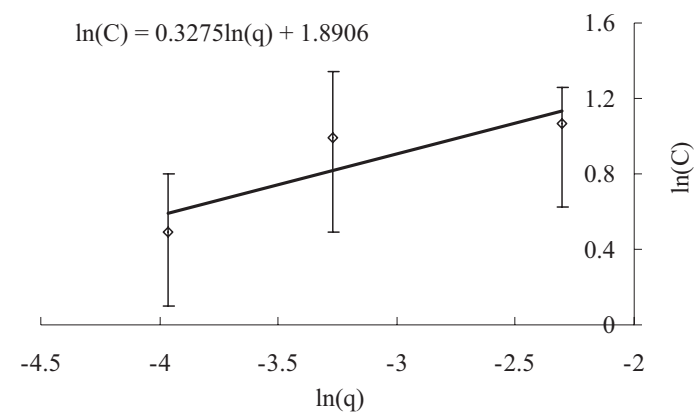

Fig. 2 Estimation of parameters $f$ and $K_{1}$ through linear regression in Model 1 with T1 as an example (The estimation accuracy might be affected by the limited three sets of $q$ values applied in the field) taking the natural logarithm to each side of Equation (3).

$$
\frac{\ln \left(S_{0}\right)-\ln \left(S_{e}\right)}{H q^{-f}}=K_{3} \theta^{T-20}
$$

Let $\frac{\ln \left(S_{0}\right)-\ln \left(S_{e}\right)}{H q^{-f}}$ to be lumped as $C$ and follow the transformation of Equation (10), Equation (12) can be rewritten as Equation (13).

$$
\ln (C)=\ln (\theta)(T-20)+\ln \left(K_{3}\right)
$$

$K_{3}$ and $\theta$ can be calculated from the interception and slope of the $\ln (C)$ versus $(T-20)$ plotting. Figure 3 is the example plotting for Model 3 using the data of T1 trench. The parameters in Model 4 can be estimated by the same method.

In Models 5 and 6, the temperature coefficient $\theta$ can be regarded as constants when $\theta$ has been estimated from Model 3 . Just following the same estimation method as above, Model 6 can be rewritten as Equation (14).

$$
\begin{aligned}
& \ln \frac{\ln \left(S_{0}-S_{n}\right)-\ln \left(S_{e}-S_{n}\right)}{H q^{-f} \theta^{T-20}} \\
& =m \ln \left(S_{0}-S_{n}\right)+\ln \left(K_{6}\right)
\end{aligned}
$$

When $\mathrm{C}=\frac{\ln \left(S_{0}-S_{n}\right)-\ln \left(S_{e}-S_{n}\right)}{H q^{-f} \theta^{T-20}}$, Equation (14) is simplified as Equation (15).

$$
\ln (C)=m \ln \left(S_{0}-S_{n}\right)+\ln \left(K_{6}\right)
$$

The parameters $m$ and $K_{6}$ can be estimated

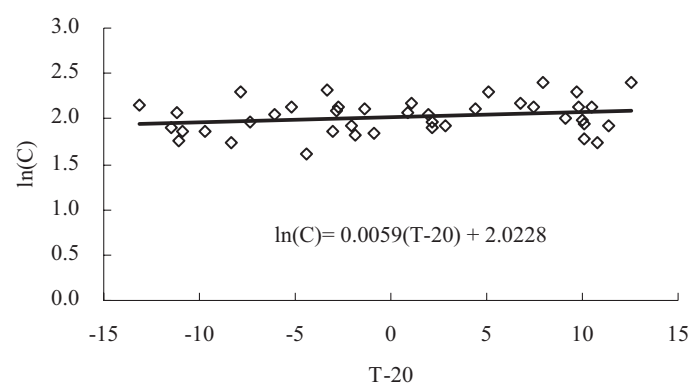

Fig. 3 Estimation of parameters $K_{3}$ and $\theta$ through linear regression in Model 3 with T1 as an example 
by following the method mentioned above. Figure 4 shows this graphical method for the estimation of $m$ and $K_{6}$ in Model 6 for T1 trench. Besides, $m$ and $K_{5}$ in Model 5 can also be estimated by the same way just letting $S_{n}=0$ in Model 6 .

In addition, $S_{n}$ values are finally determined by trial tests to get minimum values of $S D$ and $R D_{\text {avg. }}$. For T1 trench, the $S D$ and $R D_{\text {avg }}$ were the minimum when $S_{n}=15 \mathrm{mgl}^{-1}$,

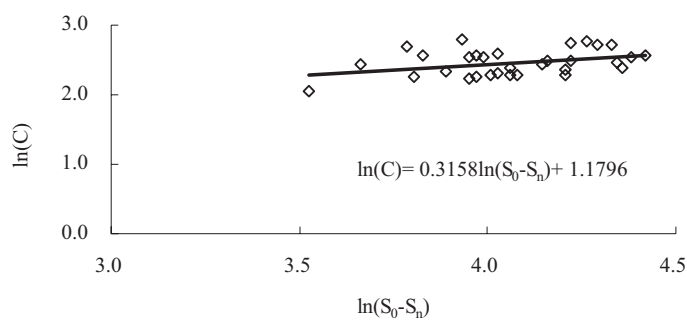

Fig. 4 Estimation of parameters $m$ and $K_{6}$ in Model 6 with $\mathrm{T} 1$ trench as an example $m=0.3158$, and $\ln \left(K_{6}\right)=1.1796\left(K_{6}=3.2531\right)$. Till now, all the parameters in the six models can be calculated.

Accuracy evaluation of the integrated COD removal model Taking the simulation in $\mathrm{T} 1$ trench as an example, the parameters of the above six models were shown in Table 3 . With water temperature (T), temperature coefficient $(\theta)$, influent $\operatorname{COD}\left(S_{0}\right)$ and nondegradable COD portion $\left(S_{n}\right)$ being considered together (e.g., Model 6), the $S D$ and $R D_{\text {avg }}$ could be reduced to 3.39 and $9.23 \%$, respectively. The data of simulation with Model 6 and that of experimental effluent COD concentrations were plotted in Fig. 5 for T1 trench. The results indicated that the $S D$ values were less than $2 \mathrm{mg}^{-1}$ for $43 \%,<3 \mathrm{mg} l^{-1}$ for $66 \%,<4 \mathrm{mg} l^{-1}$ for $84 \%$ and $<5 \mathrm{mg} l^{-1}$ for $95 \%$ of the data. Only 2 sets of the data with $S D$ larger than $5 \mathrm{mg} l^{-1}$ might be caused by the fact that the influents and corresponding effluents were

Table 3 Comparison of simulations of different models for T1 trench

\begin{tabular}{lccc}
\hline \multicolumn{1}{c}{ Models } & $n$ & $S D$ & $R D_{\text {avg }}(\%)$ \\
\hline Model 1: $S_{e}=S_{0} e^{-6.6233 \times H q^{0.3275}}$ & $44^{\mathrm{a}}$ & 6.77 & 16.56 \\
Model 2: $S_{e}=S_{0} e^{-16.2859 \times 1.035^{T-20} H q^{0.6472}}$ & $44^{\mathrm{a}}$ & 11.18 & 29.67 \\
Model 3: $S_{e}=S_{0} e^{-7.5595 \times 1.0059^{T-20} H q^{0.3275}}$ & $44^{\mathrm{a}}$ & 5.28 & 13.81 \\
Model 4: $S_{e}=S_{0} e^{-0.3341 \times H q^{0.3275} S_{0}^{0.7252}}$ & $44^{\mathrm{a}}$ & 3.72 & 10.40 \\
Model 5: $S_{e}=S_{0} e^{-0.3303 \times 1.0059^{T-20} H q^{0.3275} S_{0}^{0.7375}}$ & $44^{\mathrm{a}}$ & 3.51 & 9.82 \\
Model 6: $S_{\mathrm{e}}=\left(S_{0}-15\right) e^{-3.2531 \times 1.0059^{T-20} \mathrm{Hq}^{0.3275}\left(S_{0}-15\right)^{0.3158}+15}$ & $44^{\mathrm{a}}$ & 3.39 & 9.23 \\
\hline
\end{tabular}

a. $44(n)$ was the sum of sampling times from Runs I to V in Table 2.

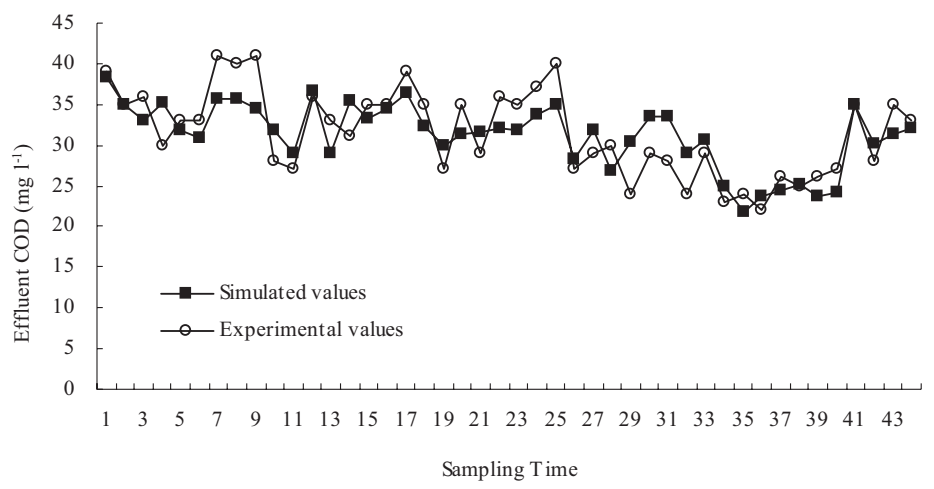

Fig. 5 Comparison of simulated and experimental values of effluent COD for T1 trench 
not the counterparts when sudden changes occurred in influent COD concentrations or temperatures. The other three SSIT systems (T2, T3 and T4) had the similar results when using this integrated COD removal model.

Effects of parameters on SSIT systems All the parameters in Model 6 for the four SSIT systems were illustrated in Table 4 . It can be seen that the temperature coefficient for BOD removal (1.035 in Model 2) was obviously not satisfied with the results of COD removal when COD values instead of BOD were directly used in Model 2. The result indicated that the introduction of temperature coefficient for COD removal $(\theta)$ was necessary for the prediction of COD removal through SSIT systems. The temperature coefficient for COD removal $(\theta)$ was 1.0059 in T1 trench, much smaller than that of Eckenfelder Model for BOD removal (1.035), implying that water temperature had less effect on COD removal through T1 trench, which is somewhat in agreement with the findings in SIT systems operated from $-13.5^{\circ} \mathrm{C}$ to $49^{\circ} \mathrm{C}^{3,31,32)}$. The other three SSIT trenches exhibited similar trends (Table 4). For SSIT systems in this study, COD removal rate at $30^{\circ} \mathrm{C}$ was only 1.19 times of that at $0^{\circ} \mathrm{C}$ in $\mathrm{T} 1$ trench under the same other operation conditions.

In $\mathrm{T} 1$ trench, hydraulic loading rate $(q)$ may exert more influence on effluent COD than in SIT systems, which can be inferred from the negative $f$ value obtained (Table 3 ). A longer retention time (lower q) would be preferred for SSIT if the effluent should meet the stringent requirement of receiving waterbodies (lower $S_{e}$ ). So the selection of adequate packing medium is very important to ensure enough retention time for pollutants under the operating $q$ conditions. All the other three trenches showed the similar results (Table 4). However, the obtained $f$ values were significantly different from the reported values for biofilm processes (always positive), which has been taken into further investigation in our laboratory.

Unlike the findings of $\mathrm{Xu} \mathrm{Y}$. and $\mathrm{Han} \mathrm{Y} .{ }^{28)}$, influent COD $\left(S_{0}\right)$ did have effect on the COD removal through SSIT system. And the impact of $S_{0}$ on effluent COD could be reduced if the nondegradable COD portion $\left(S_{n}\right)$ was excluded from the influent COD pool, which
Table 4 Comparison of the parameters using the integrated COD removal models for the four SSIT systems

\begin{tabular}{cccccc}
\multicolumn{6}{c}{ Model 6: $S_{e}=\left(S_{0}-S_{n}\right) e^{-K_{6} \theta^{T-20} \mathrm{Hq}^{-f\left(S_{0}-S_{n}\right)^{\mathrm{m}}}+S_{n}}$} \\
Systems & $K_{6}$ & $\theta$ & $f$ & $m$ & $S_{n}$ \\
\hline $\mathrm{T} 1$ & 3.2531 & 1.0059 & -0.3275 & 0.3158 & 15 \\
$\mathrm{~T} 2$ & 4.0112 & 1.0108 & -0.3071 & 0.2313 & 18 \\
$\mathrm{~T} 3$ & 2.2385 & 1.0159 & -0.2801 & 0.4085 & 18 \\
$\mathrm{~T} 4$ & 0.4173 & 1.0122 & -0.4919 & 0.8122 & 8 \\
\hline
\end{tabular}

can be deduced from the decrease trend of $m$ value from 0.7375 to 0.3158 in Models 5 and 6, respectively (Table 3). The $S_{n}$ obtained in $\mathrm{T} 1$ showed that the effluent COD from $\mathrm{T} 1$ could not less than $15 \mathrm{mg} l^{-1}$, which might be determined by the soil constituent of $\mathrm{T} 1$ trench and the characteristic of wastewater being treated (Table 3). The other three trenches also had their own $S_{n}$ values (Table 4), suggesting the different limitations of COD removal through different SSIT systems under the same operation conditions.

Importance of model parameters on COD removal for various SSIT systems Compared with $K_{6}$ and $S_{n}$, which were constants in a determined SSIT system, $\theta, m$ and $f$ should be paid more attention in the COD removal control through SSIT systems.

It can be seen from the $\theta$ values (Table 4) that water temperature had less effect on COD removal in SSIT systems with no packing media (T1), implying that the complex microenvironments caused by packing media could be more sensitive to temperature. And biological COD removal, affected more by temperature, might be predominant in the three SSIT systems with packing media (T2, T3 and T4), which has been manifested by our additional experiments ${ }^{18)}$.

The $f$ and $m$ values in Table 4 showed that the effects of $q$ and $S_{0}$ on COD removal relied on the packing medium being used in SSIT system. For example, $q$ had less influence on COD removal in T3 with anthracite added and did the opposite in T4 (zeolite). From our field results, COD removal showed increase trend with $q$ varied from $0.019 \mathrm{~m}^{3} \mathrm{~m}^{-2} \mathrm{~d}^{-1}$ to $0.1 \mathrm{~m}^{3} \mathrm{~m}^{-2} \mathrm{~d}^{-1}$ for the four SSIT systems, resulting in the negative values of $f$, while 
higher COD removals were achieved in SIT systems at lower $q^{33,34)}$, which limited the wide application of SIT systems ${ }^{35)}$. All the values of $f$ for the four SSIT systems were negative, resulted partly from the nature of artificial soil (local soil, coal slag, dewatered sludge, etc.), and partly from the shallow depth of soil matrix. In addition, the abiological degradation contributed to $28.1 \%^{-}$ $42.3 \%$ of the total COD removal ${ }^{18)}$, which has been included in the integrated COD removal model while always not in BOD removal models (e.g., Eckenfelder Model). This disagreement phenomenon between SIT and SSIT systems needs more detailed investigation before really adequate conclusion could be deduced.

COD removal rate could also be altered by using packing media in SSIT systems. In this study adding sawdust (T2) had increase effect on $K_{6}$, while the other two packing materials did the opposite, especially for zeolite. It has been reported that zeolite had strong adsorption capability of phosphorus ${ }^{36)}$, and the SSIT system with zeolite packed (T4) also showed a strong COD removal potential, with the lowest $S_{e}$ being $8 \mathrm{mg} l^{-1}\left(S_{n}\right)$ even under higher $q$ and higher $S_{0}$ conditions, which might be contributed by two kinds of competitions, one is between strong adsorption and limited biological removal for the treated wastewater, another is between COD removal and nutrient removals ( $\mathrm{N}$ and $\mathrm{P})$. The detailed reason is also under further investigation in our laboratory.

COD removal predictions for the four SSIT systems According to the parameters listed in Table 4, the predictions of COD removals for different SSIT systems could be realized. Based on the data from our actual field program and laboratory studies, the conservative application limitation of Model 6 for the four SSIT systems were as follows if the effluent COD must be less than $40 \mathrm{mg}$ $l^{-1}$ : (1) $q$ from $0.1 \mathrm{~m}^{3} \mathrm{~m}^{-2} \mathrm{~d}^{-1}$ to $1.0 \mathrm{~m}^{3} \mathrm{~m}^{-2} \mathrm{~d}^{-1}$; (2) $T$ from $5^{\circ} \mathrm{C}$ to $35^{\circ} \mathrm{C}$; and (3) $S_{0}$ from $30 \mathrm{mg}$ $l^{-1}$ to $100 \mathrm{mg} l^{-1}$.

The predicted COD removals for the four trenches under extreme operation conditions were summerized in Table 5 . It can be seen that COD removal rates changed with operation conditions, even for the same
Table 5 Predicted COD removals in different SSIT systems under extreme operation conditions

\begin{tabular}{ccc|cccc}
\hline \multicolumn{3}{c|}{ Operation Conditions } & \multicolumn{4}{c}{ COD removal rate (\%) } \\
$q$ & $T$ & $S_{0}$ & $\mathrm{~T} 1$ & $\mathrm{~T} 2$ & $\mathrm{~T} 3$ & $\mathrm{~T} 4$ \\
\hline$\left(\mathrm{m}^{3} \mathrm{~m}^{-2} \mathrm{~d}^{-1}\right)$ & $\left({ }^{\circ} \mathrm{C}\right)$ & $\left(\mathrm{mg} l^{-1}\right)$ & & & & \\
\hline 0.1 & 5 & 30 & 31.4 & 23.7 & 21.4 & 24.9 \\
0.1 & 5 & 100 & 69.6 & 61.8 & 66.8 & 67.5 \\
0.1 & 35 & 30 & 34.6 & 28.4 & 28.3 & 32.9 \\
0.1 & 35 & 100 & 73.9 & 70.1 & 76.5 & 78.3 \\
1.0 & 5 & 30 & 43.9 & 33.5 & 30.7 & 53.0 \\
1.0 & 5 & 100 & 82.8 & 77.2 & 78.7 & 90.5 \\
1.0 & 35 & 30 & 45.9 & 36.8 & 36.2 & 61.8 \\
1.0 & 35 & 100 & 83.9 & 80.4 & 81.5 & 91.8 \\
\hline
\end{tabular}

system. The highest removal rate could reach $91.8 \%$ in T4 under highest $q, T$ and $S_{0}$ within the model application limits. However, SSIT systems might also be faced with the risk of soil clogging as SIT system, and the suitability of this model to predict long-term sustainable operation under high loading rate should be further investigated and testified by field results before being applied.

Differences among the four SSIT systems from the point of integrated COD removal model With different packing medium added in soil, the difference of the COD removal mechanisms for the four SSIT systems could be discerned from the obtained parameters $\left(K_{6}, \theta, f, m\right.$ and $\left.S_{n}\right)$ by using the integrated COD removal model and the field experimental data.

From Table 5, it can be seen that the COD removal rates for SSIT systems under high $S_{0}$ condition (100 $\mathrm{mg} \mathrm{l}^{-1}$ ) were generally $2 \sim 3$ times of those under low $S_{0}$ condition $(30 \mathrm{mg}$ $\left.l^{-1}\right)$.

The simulation results showed that the exponent $m$ could be used as an indicator of anti-fluctuation capability of a SSIT system to the changing influent COD concentrations. The larger the $m$ value, the more stable of the effluent COD from SSIT. Among the four SSIT systems, T4, with zeolite added and the largest $m$ value, demonstrated the strongest ability of anti-fluctuation of influent COD concentrations (Fig. 6 (a)).

Besides, it can also be obtained that the COD removal rates for SSIT systems under high $q$ condition $\left(1.0 \mathrm{~m}^{3} \mathrm{~m}^{-2} \mathrm{~d}^{-1}\right)$ were about 
1.5 2 times of those under low $q$ condition $\left(0.1 \mathrm{~m}^{3} \mathrm{~m}^{-2} \mathrm{~d}^{-1}\right)$ (Table 5). Compared with the other three SSIT systems, which discharged relatively stable effluent COD concentrations, T4 exhibited a higher COD removal potential and its effluent COD showed an obvious decrease trend with the increase of $q$ within the simulation limits (Fig. 6 (b)).

Being similar with the phenomena observed in the field program, the predicted values showed that water temperature had relatively less effect on COD removal in SSIT systems partly because of the less variations of model parameter $\theta$ (Fig. 6 (c)). The COD removal
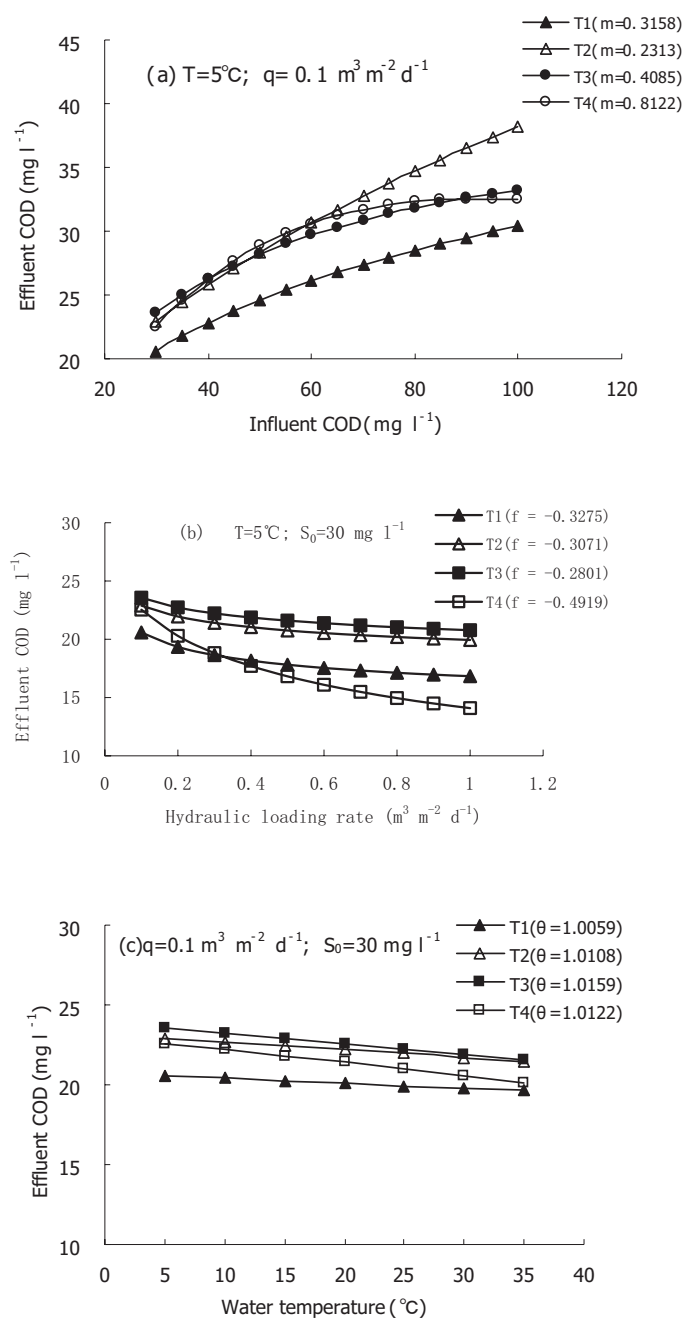

Fig. 6 Differences among the four SSIT systems under the same operation condition from Model 6 prediction rates increased slightly with temperature, and all the SSIT systems showed relatively stable COD removal performance within the temperature limit $\left(5^{-} 35^{\circ} \mathrm{C}\right)$.

\section{CONCLUSIONS}

An integrated COD removal model was established for SSIT system in this paper, in which three factors, influent COD concentration $\left(S_{0}\right)$, water temperature $(T)$ and nondegradable COD portion $\left(S_{n}\right)$, were incorporated into Eckenfelder Model. The simulation accuracy was greatly improved when considering the three factors together, that is $S D=3.39$ and $R D_{\text {avg }}=9.23 \%$ when using Model 6, the integrated COD removal model, and the deviations between simulation and experiment could be within $5 \mathrm{mg} l^{-1}$ for $95 \%$ of the data obtained.

With shallow depth of soil matrix, the COD removal efficiency for SSIT system was more influenced by soil constituents rather than operation conditions, and the model parameters, $f$ and $m$, corresponding to hydraulic loading rate $(q)$ and influent COD $\left(S_{0}\right)$ respectively, impacted more on a determined SSIT system. Zeolite was proved to be an effective packing medium in SSIT system for COD removal, especially under higher $q$ or higher $S_{0}$ conditions. The relationship between effluent $\operatorname{COD}\left(S_{e}\right)$ and $q$ failed to agree with the theoretical mechanisms of biofilm filters or SIT systems, which needs further detailed investigation. From the viewpoint of practice, the integrated COD removal model proposed in this study should be researched and manifested widely by field experiments before its application.

\section{REFERENCES}

1 ) Horasawa I.: Wastewater biological treatment (ZHANG Z. J. translated), China Architecture \& Building Press, Beijing, 45-53 (1980) (in Chinese).

2 ) Van Cuyk S., Siegrist R., Logan A., Masson S., Fischer E. and Figueroa L.: Hydraulic and purification behaviors and their interactions during wastewater treatment in soil infiltration systems, Water Res., 35(4), 953-964 (2001). 
3 ) Tian N. N., Yang L. P. and Peng Y. D.: Treatment of domestic wastewater by soil infiltration system, China Water Wastewater, 16, 12-15 (2000) (in Chinese).

4 ) Kristiansen R. : Sand-filter trenches for purification of septic tank effluent I. The clogging mechanism and soil physical environment, Environ. Qual., 10(3), 353357 (1981).

5 ) Brissand F.: Infiltration percolation for reclaimed pond, Water Sci. Tech., 24(9), 185-193 (1991).

6 ) Culp R. L., Wesner G. M. and Culp G. L. : Handbook of advanced wastewater treatment (ZHANG Z. H. translated), China Architecture \& Building Press, Beijing, 330-379 (1991) (in Chinese).

7 ) Kanarek A. and Michail M.: Groundwater recharge with municipal effluent: Dan Region reclamation project, Israel, Water Sci. Tech., 34(11), 227-233 (1996).

8 ) Jia H. Y., Sun T. H., Li P. J., Tai P. D., Zhou Q. X., Chang S. J. and Ma X. J.: New advances in the land treatment technology for wastewater, Techniq. Equip. Environ. Pollut. Control, 2(1), 62-65 (2001) (in Chinese).

9 ) Vigneswaran S. and Ronillo B. S. : A detailed investigation of physical and biological clogging during artificial recharge, Water Air Soil Pollut., 35,119-140 (1987).

10) Lal R.: Agroforestry systems and soil surface management of a tropical alfisol, Agroforestry systems, 8, 217-238 (1989).

11) Chung J. B., Kim S. H., Jeong B. R., Lee Y. D. and Prasher S. O.: Modeling floodplain filtration for the improvement of river water quality, Trans. Porous Media, 60, 319-337 (2005).

12) Wanko A., Mose R., Carrayrou J. and Sadowski A. G.: Simulation of biodegradation in infiltration seepage model development and hydrodynamic calibration, Water Air Soil Pollut., 177, 19-43 (2006).

13) Muzaffar M. E. and Kevin E. L.: Optimal operation of artificial groundwater recharge systems considering water quality transformations, Water Res. Manage., 18, 379-405 (2004).

14) Xu L., Li G. H., Mays L. W. and Asce M.: Optimal operation of soil aquifer treatment systems considering parameter uncertain- ty, Water Res. Manage., 15, 123-147 (2001).

15) Oudot J., Ambles A., Bourgeois S., Gatellier C. and Sebyera N.: Hydrocarbon infiltration and biodegradation in a land-farming treatment, Environ. Pollut., 59:17-40 (1989).

16) Zheng Y. X., Feng S. Y., Cai J. B. and Huang B. B.: Experimental study on removal of organic substance in reservoir water by means of soil aquifer treatment system, $J$. Hydraulic Eng., 36, 1083-1087 (2005) (in Chinese).

17) Liu C. X., Hu H. Y., Zhang J., Huang X., Shi H. C. and Qian Y.: Rural sewage treatment performance of constructed wetlands with different depths, Environ. Sci., 24(5), 9296 (2003) (in Chinese).

18) Zhang Z., Lei Z., Zhang Z., Sugiura N., Xu X. and Yin D.: Organics removal of combined wastewater through shallow soil infiltration treatment: a field and laboratory study, J. Hazard. Mater. doi: 10. 1016/j.jhazmat, 2007.04 .026 (2007).

19) Mclaren A. D., Peterson G. H., Skujins J. and Paul E. A.: Soil biochemistry(Min J. K., et al. translated), Agriculture Press, Beijing, pp268-271 (1984) (in Chinese).

20) Qin L. Y.: Wastewater biological treatment, Tongji University Press, Shanghai, pp210240 (1989) (in Chinese).

21) Qiu L., Du M., Ma J. and Zhang L.: Kinetic characteristic of single biological aerated filter (BAF) for domestic wastewater treatment, J. Harbin Inst. Technol., 38(2), 203-207 (2006). (in Chinese).

22) Wang L. and Hu Y.: Study on the effect of organic removal and ammonia nitrogen nitrified by biological aerated filter, Environ. Pollut. Preven., 28(4), 257-260 (2006) (in Chinese).

23) Jiang P. and Hu J.: Kinetics research on the treatment of domestic sewage by biological aerated filter, J. Nanchang Univ. (Engin. Technol.), 24(1), 62-67 (2002) (in Chinese)

24) Xu Y. and Wu H.: The relationship between the organic removal, reaction rate parameter and film thickness in biological aerated filter, Techni. Equip. Environ. Pollut. 6(6), 76-79 (2006) (in Chinese).

25)Gromiec M.J. and Roman M.: Application of correlation-regression method for deter- 
mination of coefficients for the Eckenfelder trickling filter models, Water Res. 13, 1105-1110 (1979).

26) Zhang J., Huang X., Wei J., Hu H. Y. and Shi H. C.: Nitrogen and phosphorus removal mechanism in subsurface wastewater infiltration system, China Environ. Sci., 22(5), 438-441 (2002) (in Chinese).

27) Nema P., Ojha C. S. P., Kumar A. and Khanna P.: Techno-economic evaluation of soil-aquifer treatment using primary effluent at Ahmedabad, India, Water Res., 35(9), 2179-2190 (2001).

28) Xu Y. and Han Y.: Study on removing organic matter and ammonia nitrogen with the aerobic biofilm filter bed, $J$. Dalian Fisheries Univ., 12(1), 43-50 (1997) (in Chinese).

29) Joerg E. D. and Martin J.: Behavior of DOC and AOX using advanced treated wastewater for groundwater recharge, Water Res., 32(10), 3125-3133 (1998).

30) Shariatmadari H., Shirvani M. and Jafari A.: Phosphorus release kinetics and availability in calcareous soils of selected arid and semiarid toposequences, Geoderma, 132, 261-272 (2006).

31) Viswanathan M. N., Al Senafy M. N., Rashid T., Al-Awadi E. and Al-Fahad K.: Im- provement of tertiary wastewater quality by soil aquifer treatment, Water Sci. Tech., 40(7), 159-163 (1999).

32) Zhang W., Bouwer E., Wilson L. and Durant N.: Biotransformation of aromatic hydrocarbons in subsurface biofilms, Water Sci. Tech., 31(1), 1-14 (1995).

33) Cui L. H., Tang L. M., Zhu X. Z., Zhang Z. X. and Bai Y.: Test of dosing regime of artificial soil filter treating municipal wastewater, Agro-environ. Protect., 21(1), 37-40 (2002) (in Chinese).

34) Liu Y., Li G. X.and Cui L. H.: Purification effect of a rapid infiltration system using artificial soil with different irrigating period on treatment of municipal sewage, Agro-environ. Protect., 19(6), 332-335 (2000) (in Chinese).

35) Wang S. W., Liu Q. Y., Jiao Y. Z. and Sun T. H.: The latest progress in soil infiltration treatment of sewage in situ, Tech. Water Treat., 32(3), 5-10 (2006) (in Chinese).

36) Sakadevan K. and Bavor H. J. : Phosphate adsorption characteristics of soils, slags and zeolite to be used as substrates in constructed wetland systems, Water Res., 32 (2), 393-399 (1998).

(Submitted 2007. 4. 23)

(Accepted 2007. 11. 3) 
